Reka Buana : Jurnal Ilmiah Teknik Sipil dan Teknik Kimia, 5 (1), 2020, page 57-62

Tersedia online di https://jurnal.unitri.ac.id/index.php/rekabuana

ISSN 2503-2682 (Online)

ISSN 2503-3654 (Cetak)

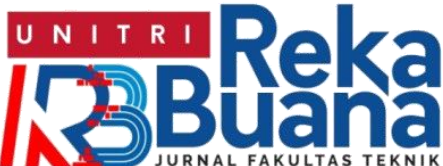

\title{
Karakteristik Bioetanol Gel dari Buah Berenuk (Crescentia cujete L.)
}

\author{
Nurkholis ${ }^{1 *}$, Abdul Fajar ${ }^{2}$ dan Sopyan Ali Rohman ${ }^{3}$ \\ 1,2 Program Studi Teknologi Industri Pertanian, Fakultas Teknologi Pertanian, Universitas Teknologi Sumbawa. \\ ${ }^{3}$ Program Studi Teknik Mesin, Fakultas Teknik, Universitas Teknologi Sumbawa. \\ *e-mail corresponding author : nurkholis@uts.ac.id.
}

\begin{abstract}
ABSTRAK
Berenuk (Crescentia cujete L.) merupakan salah satu tumbuhan non-pangan yang dapat dikonversi menjadi bioetanol, dimana kandungan karbohidrat dalam dagingnya cukup tinggi yaitu 15,56\% (wet basis) dan $68,31 \%$ (dry basis). Bioetanol yang dihasilkan berwujud cair, sehingga pada saat digunakan akan beresiko tumpah dan mudah terbakar. Sifat fisik bioetanol dapat dimodifikasi menjadi gel dengan penambahan bahan pengental seperti carboxymethyl cellulose (CMC), sehingga relatif aman ketika digunakan. Tujuan dari penelitian ini adalah untuk menghasilkan bioetanol gel dari buah berenuk (Crescentia cujete L.) dan mengetahui karakteristik dari biotenol gel tersebut, yang meliputi: kadar air, kadar abu, dan nilai kalor. Pada penelitian ini, bioetanol gel dibuat dengan mencampurkan bioetanol cair dengan bahan pengental CMC menggunakan magnetic stirrer selama \pm 15 menit dengan kecepatan $600 \mathrm{rpm}$. Dari hasil penelitian ini dapat disimpukan bahwa karakteristik bioetanol gel terbaik diperoleh pada penambahan CMC sebanyak 3 gram $(6 \%$ b/v) yaitu kadar air $94,94 \%$, kadar abu $0,75 \%$ dan nilai kalor $2.334 \mathrm{kal} / \mathrm{gr}$.
\end{abstract}

Kata kunci: karakteristik; bioetanol gel; buah berenuk.

\begin{abstract}
Berenuk (Crescentia cujete L.) is one of the non-food plants that can be converted into bioethanol, where the carbobydrate in the pulp is quite high at $15.56 \%$ (wet basis) and 68.31\% (dry basis). The bioethanol produced is liquid, so when used it will be at risk of spilling and flammable, because it is volatile. The physical properties of bioethanol can be modified into gels by adding thickening agents such as carboxymetbyl cellulose (CMC), so they are relatively safe when used. The aim of this study was to produce bioethanol gel from berenuk fruit (Crescentia cujete L.) and determine the characteristics of the biotenol gel, which includes: water content, ash content, and heating value. In this study, bioethanol gel was made by mixing liquid bioethanol with CMC thickener using magnetic stirrer for \pm 15 minutes at a speed of $600 \mathrm{rpm}$ From the results of this study it can be concluded that the best characteristics of bioethanol gel were obtained by adding 3 grams of CMC $(6 \% \mathrm{w} / \mathrm{v})$, namely $94.94 \%$ moisture content, $0.75 \%$ ash content and 2,344 call gr heat value.
\end{abstract}

Keywords: characteristics; bioethanol gel; berenuk

Cara Mengutip : Nurkholis, N., Fajar, A., Rohman, S. A. (2020). Karakteristik Bioetanol Gel dari Buah

Berenuk (Crescentia cujete L.). Reka Buana : Jurnal Ilmiab Teknik Sipil dan Teknik Kimia, 5(1), 57-62.

http://dx.doi.org/10.33366/rekabuana.v5i1.1613

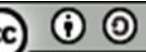

C. CY SA Content from this work may be used under the terms of the Creative Commons Attribution-ShareAlike 4.0 International License. Any further distribution of this work must maintain attribution to the author(s) and the title of the work, iournal citation and DOI. 
Bahan bakar minyak (BBM) merupakan kebutuhan yang sangat penting bagi masyarakat. Saat ini kebutuhan akan bahan bakar minyak (BBM) masih dipasok dari sumber energi fosil yang bersifat tidak dapat diperbarui (unrenewable) yaitu minyak bumi. Bahan bakar minyak (BBM) mengalami kelangkaan, karena menipisnya deposit minyak bumi dan tidak stabilnya harga minyak dunia (tidak ekonomis). Penghematan konsumsi bahan bakar minyak (BBM) dapat dilakukan dengan mencari sumber energi alternatif yang dapat diperbarui (renewable) dan sustainable, misalnya dengan konversi biomassa menjadi bioetanol.

Bioetanol adalah etanol sederhana yang merupakan sumber energi terbarukan dan dihasilkan dari fermentasi komponen gula pada tumbuhan [1]. Berbagai penelitian yang telah dilakukan menggunakan bahan baku yang berasal dari hasil pertanian yang berbasis gula, seperti: jagung, singkong, tebu, kedelai, gandum, sorgum dan kacangkacangan. Ketergantungan yang begitu besar pada hasil pertanian akan menyebabkan krisis pangan karena persaingan komoditas untuk kepentingan bahan bakar dengan permintaan untuk pakan ternak dan konsumsi makanan manusia [2]. Salah satu alternatif untuk menangani masalah tersebut adalah dengan menggunakan bahan non-pangan yang berpotensi sebagai bahan baku bioetanol.

Berenuk (Crescentia cujete L.) merupakan tumbuhan non-pangan yang berpotensi sebagai bahan baku bioetanol. Berenuk umumnya dijumpai didaerah beriklim tropis. Selama ini, buah berenuk yang tumbuh liar hanya dimanfaatkan oleh masyarakat sebagai obat herbal atau kulit buahnya dijadikan kerajinan tangan. Pemanfaatan buah berenuk yang belum optimal dikarenakan kurangnya pengetahuan masyarakat akan potensi buah berenuk, dimana dalam buah berenuk terkandung karbohidrat sebesar 15,56\% (wet basis) dan 68,31\% (dry basis) [3]. Selain itu, buah ini tumbuh sepanjang tahun dan dalam jumlah yang melimpah karena bukan merupakan komoditas dan tidak dapat dikonsumsi. Berdasarkan hal tersebut, buah berenuk sangat berpotensi untuk dijadikan bahan baku bioetanol.

Bioetanol yang dihasilkan berwujud cair, sehingga pada saat digunakan sebagai bahan bakar rumah tangga akan beresiko tumpah dan mudah terbakar, karena sifatnya yang volatil. Untuk meningkatkan keamanan ketika digunakan, sifat fisik bioetanol dapat dimodifikasi menjadi gel, sehingga dapat digunakan untuk memasak dan dapat dibawa kemana-mana [4]. Modifikasi bentuk bioetanol menjadi gel dapat dilakukan dengan penambahan bahan pengental seperti misalnya carboxymethyl cellulose.

Dari penelitian ini, diketahui karakteristik bioetanol gel dari buah berenuk (Crescentia cujete L.), yang meliputi: nilai kalor, laju pembakaran dan residu hasil pembakaran. Hal ini bertujuan untuk menilai kelayakan (feasibility) dari bietanol gel tersebut terkait dengan penggunaanya sebagai bahan bakar alternatif.

\section{METODE PENELITIAN}

\subsection{Alat}

Alat yang digunakan dalam penelitian ini meliputi: blender, fermentor dengan kapasitas $500 \mathrm{~mL}$, seperangkat alat distilasi, magnetic stirrer, termometer, piknometer, neraca digital dengan ketelitian 0,001 gram, gelas arloji, erlenmeyer, kalorimeter bom IKA C2000, desikator dan stopwatch.

\subsection{Bahan}


Bahan utama yang digunakan dalam penelitian ini adalah daging buah berenuk (Crescentia cujete L.) yang diambil dari Kec. Moyo Hulu, Kabupaten Sumbawa, Nusa Tenggara Barat. Bahan pengental yang digunakan untuk membuat bioetanol gel yaitu carboxymethyl cellulose (CMC) food grade dengan kemurnian 99,5\% yang diperoleh dari Toko Cipta Kimia, serta bahan-bahan lain seperti: urea, NPK, dan ragi roti (Saccharomyces cerevisiae).

\subsection{Prosedur Penelitian}

Pelaksanaan penelitian dilakukan dalam 2 tahap. Tahap pertama yaitu pembuatan bioetanol dengan cara fermentasi. Daging buah yang telah dihaluskan dengan blender difermentasi dalam fermentor menggunakan Saccharomycess cereviceae serta urea dan NPK sebagai nutrisi untuk mikroorganisme.

Proses fermentasi dilakukan secara batch selama 3 hari pada kondisi anaerob dan suhu ruang. Cairan hasil fermentasi kemudian dimurnikan dengan distilasi fraksional pada suhu $78-80{ }^{\circ} \mathrm{C}$ dan di ukur kadarnya dengan metode piknometer. Selanjutnya, tahap kedua yaitu pembuatan bioetanol gel dengan cara mencampurkan bioetanol cair dan bahan pengental carboxymethyl cellulose sesuai variasi dan akuades sebanyak $20 \mathrm{~mL}$ sambil diaduk dengan magnetic strirrer selama \pm 15 menit dan kecepatan pengadukan $600 \mathrm{rpm}$. Bioetanol gel yang dihasilkan dianalisis karakteristiknya, meliputi: kadar air, kadar abu dan nilai kalor.

Pada penelitian ini, variabel tetap adalah volume bioetanol cair dari buah berenuk yaitu $50 \mathrm{~mL}$, variabel bebas adalah berat carboxymethyl cellulose dengan taraf 1 gram $(2 \%$ b/v), 2 gram $(4 \%$ b/v) dan 3 gram $(6 \% \mathrm{~b} / \mathrm{v})$, sedangkan variabel terikat yang diamati adalah karakteristik bioetanol gel, yang meliputi: kadar air, kadar abu dan nilai kalor.

\subsection{Analisis Hasil}

Pada penelitian ini, pngulangan perlakuan dilakukan sebanyak 3 kali, sehingga diperoleh 9 unit percobaan.

Data dan hasil percobaan akan dianalisis menggunakan Software SPSS 16.0 yaitu Analysis of Variance (ANOVA) dengan taraf 5\%. Jika terdapat beda nyata, maka akan dilanjutkan dengan Uji Duncan.

\section{HASIL DAN PEMBAHASAN}

Dalam penelitian ini, diperoleh bioetanol cair dengan densitas sebesar 0,9642 gr/ mL dengan kadar sebesar 30\% (metode piknometer). Bioetanol cair yang dihasilkan kemudian diubah ke dalam bentuk gel untuk mengetahui karakteristiknya dan kelayakan (feasibility) sebagai bahan bakar.

\subsection{Kadar Air}

Kadar air bahan bakar adalah jumlah air yang terdapat pada bahan bakar, dinyatakan sebagai presentase berat material [5]. Secara umum, semakin banyak penambahan carboxymetbyl cellulose (CMC) akan menyebabkan semakin rendah kadar air. Kadar air tertinggi diperoleh pada penambahan CMC sebanyak 1 gram yaitu $97,72 \%$, sedangkan kadar air terendah diperoleh pada penambahan CMC sebanyak 3 gram yaitu 94,94\%. Hal ini terjadi karena air akan berikatan sangat kuat dengan CMC, sehingga akan sulit menguap baik dengan pembakaran maupun pemanasan. Campuran ini adalah bagian yang sudah tidak dapat menguap setelah semua bioetanol habis menguap oleh panas. Dalam hal ini, kandungan air yang terhitung 
sebagai kadar air tidak termasuk bagian air yang terikat dalam CMC tersebut.

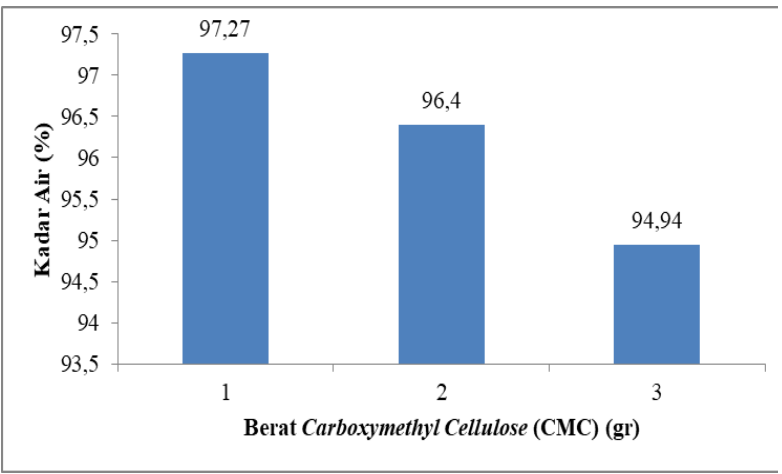

Gambar 1. Kadar Air (\%)

Hasil analisis ragam (ANOVA) pada berat CMC terhadap kandungan kadar air bioetanol gel menunjukkan nilai $\mathrm{F}$ hitung $(49,452)>$ F tabel $(5,143)$ serta nilai P-value $(0,000)<$ nilai $\alpha(0,05)$.

Dengan demikian, dapat disimpulkan bahwa berat CMC yang berbeda dapat berpengaruh terhadap kandungan kadar air bioetanol gel. Adanya pengaruh konsentrasi CMC terhadap kandungan kadar air pada bioetanol gel dari analisis ragam (ANOVA) yang dilakukan, maka dilakukan uji lanjut duncan untuk melihat perbedaan pada masing-masing perlakuan. Berdasarkan hasil uji lanjut Duncan menunjukkan berat CMC 1 gram, 2 gram, 3 gram berbeda nyata, maka dapat disimpulkan bahwa penambahan CMC pada bioetanol gel dengan konsentrasi yang berbeda dapat berpengaruh nyata terhadap kadar air bioetanol gel.

Dari segi kualitas, kadar air yang tinggi akan menurunkan kualitas bioetanol gel. Pada penelitian ini, hal ini disebabkan oleh kemurnian bioetanol cair yang relatif rendah, dimana masih terkandung cukup banyak komponen air karena sulit dipisahkan.

\subsection{Kadar Abu}

Kadar abu merupakan bagian dari sisa pembakaran yang sudah tidak memiliki unsur karbon. Semakin tinggi kadar abu maka semakin rendah kualitas bioetanol gel karena semakin tinggi kadar abu dakan dapat menurunkan nilai kalor suatu bahan bakar [6].

Semakin banyak penambahan carboxymetbyl cellulose (CMC) akan menyebabkan semakin tinggi kadar abu. Kadar abu tertinggi diperoleh pada penambahan CMC sebanyak 3 gram yaitu 0,74\%, sedangkan kadar abu terendah diperoleh pada penambahan CMC sebanyak 1 gram yaitu $0,37 \%$. Kadar abu yang terhitung merupakan residu atau sisa pembakaran karena sudah tidak memiliki unsur karbon, seperti komponen organik atau mineral. Dalam hal ini, komponen ini berasal dari CMC. Sehingga, semakin besar penambahan CMC maka semakin besar bagian yang merupakan sisa pembakaran.

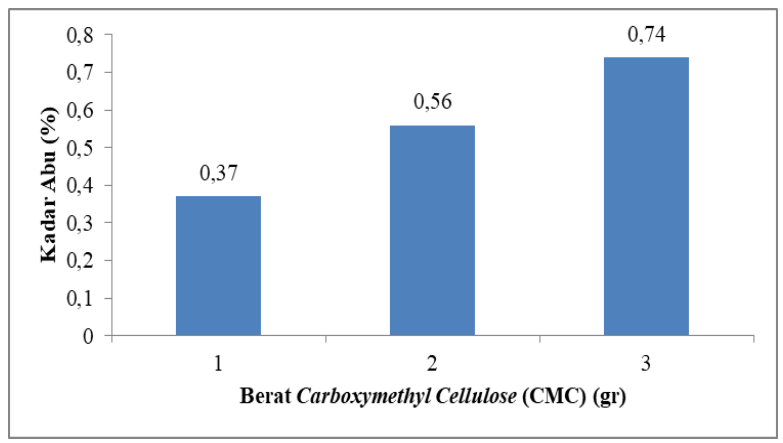

Gambar 2. Kadar Abu (\%)

Hasil analisis ragam (ANOVA) pada berat CMC terhadap kandungan kadar air bioetanol gel menunjukkan nilai $\mathrm{F}$ hitung $(88,761)>$ F tabel $(5,143)$ serta nilai P-value $(0,000)<$ nilai $\alpha(0,05)$.

Dengan demikian, dapat disimpulkan bahwa berat CMC yang berbeda dapat berpengaruh terhadap kandungan kadar air bioetanol gel. Adanya pengaruh konsentrasi CMC terhadap kandungan kadar air pada 
bioetanol gel dari analisis ragam (ANOVA) yang dilakukan, maka dilakukan uji lanjut Duncan untuk melihat perbedaan pada masing-masing perlakuan.

Hasil uji lanjut Duncan menunjukkan konsentrasi CMC 1 gram, 2 gram, 3 gram memberikan pengaruh yang berbeda nyata, maka dapat disimpulkan bahwa penambahan CMC pada bioetanol gel dengan konsentrasi yang berbeda dapat berpengaruh terhadap kadar abu bioetanol gel. Sedangkan, kadar abu bioetanol gel yang dihasilkan masih jauh dibawah standar kadar abu maksimum yaitu $<5 \%$ sesuai dengan standar mutu dari Afrika Selatan [5].

\subsection{Nilai Kalor}

Nilai kalor berhubungan erat dengan komposisi karbon terikat dan kadar air pada suatu bahan bakar. Semakin tinggi karbon terikat yang dimiliki, maka nilai kalornya juga semakin tinggi. Hal ini disebabkan dalam pembakaran dibutuhkan karbon yang bereaksi dengan oksigen untuk menghasilkan kalor Sedangkan, semakin rendah kadar air bahan bakar, maka nilai kalornya akan semakin tinggi [5].

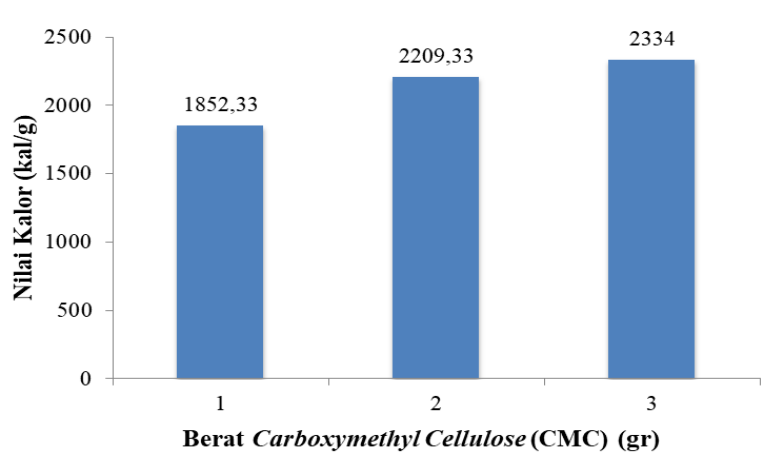

Gambar 3. Nilai Kalor (kal/ g)

Semakin banyak penambahan carboxymethyl cellulose (CMC) akan menyebabkan semakin tinggi nilai kalor. Nilai kalor tertinggi diperoleh pada penambahan CMC sebanyak 3 gram yaitu
$2.334 \mathrm{kal} / \mathrm{g}$, sedangkan kadar abu terendah diperoleh pada penambahan CMC sebanyak 1 gram yaitu $1.852,23 \mathrm{kal} / \mathrm{g}$. Menurut Referensi [5], bahwa nilai kalor bahan bakar bioetanol gel akan berasosiasi dengan nilai kadar air yang terdapat pada bioetanol gel, dimana semakin rendah kadar air maka akan menghasilkan nilai kalor yang semakin tinggi, dan sebaliknya. Selain itu, faktor lain yang dapat mempengaruh terhadap tinggi rendahnya nilai kalor adalah kandungan carbon dan oxygen.

\section{KESIMPULAN}

Berdasarkan eksperimen yang telah dilakukan, didapatkan kesimpulan bahwa penambahan bahan pengental CMC sebanyak 3 gram $(6 \% \mathrm{~b} / \mathrm{v})$ memberikan hasil terbaik yaitu kadar air 94,94\%, kadar abu $0,74 \%$ dan nilai kalor $2.334 \mathrm{kal} / \mathrm{g}$.

\section{PENGHARGAAN}

Penelitian ini dapat terlaksana dengan baik atas pendanaan dari Hibah Kompetitif Penelitian Dosen Pemula (PDP) dari Kementerian Riset Teknologi dan Pendidikan Tinggi, Indonesia.

\section{DAFTAR PUSTAKA}

[1] Chum, H. L., \& Overend, R. P. (2001). Biomass dan Renewable Fuels. Fuel Processing Technology, 71 (1), 187 195.

[2] Balat, M., \&Balat, H. (2009). Recent trends in global production and utilization of bioethanol fuel. Applied Energy, 86 (11), 2273-2282.

[3] J. Robinson. (2006). Bio-ethanol as a household cooking fuel: a mini plant study of the SuperBlu stove in periurban Malawi. Loughborough University, Leics. 
[4] Merdjan, R. E., \& Matione, J. (2003). Fuel Gas. United State Patens App. Publication No. US 2003/0217504A1.

[5] Tyastando, D. R., Ardiansah, J., Pramudita, A. E., \& Riandadari, D. (2019). Studi Eksperimental Pembuatan Bioetanol Gel dengan Pengental Carboxymetbyl Cellulose (CMC) dan Pengujian Performance Bioetanol
Gel. Indonesian Journal of Engineering and Technology (INAJET), 1 (2), 1-7.

[6] Hanun, V., \& Heru, S. D. (2018). Komparasi Karaktristik Bioetanol Gel Dengan Pegental Karbopol dan Carboxy Metbyl Celloluse (CMC) Sebagai Bahan Bakar Alternatif. JPTM, 7 (2), 14-20 